\title{
Variations in Pattern of Pubertal Changes in Girls
}

\author{
W. A. MARSHALL and J. M. TANNER \\ From the Department of Growth and Development, Institute of Child Health, University of London
}

In Great Britain some girls begin to menstruate in their 10th or 11th years, while others who are equally healthy may not experience menarche until they are 14,15, or even older. Menarche is, however, only a single event in the combination of physical changes which constitute puberty. The adolescent growth spurt, the development of the breasts, and the growth of the pubic hair occur more or less concurrently, and take, on the average, about 3 years from beginning to completion, with menarche occurring usually in the latter half of this period (Tanner, 1962).

At present we lack detailed information about the rate at which girls progress through the stages of puberty and about the relation of one event to another. Only longitudinal studies (i.e. studies in which the same individuals are examined repeatedly over a period of time) can provide this information, which would be helpful both to the clinician in distinguishing the normal from the abnormal, and to the neuro-endocrinologist in constructing hypotheses about the mechanisms by which puberty is controlled. Present knowledge is based on studies carried out on small numbers of children in the United States a generation ago, together with some German studies of a similar period (for literature see Tanner, 1962).

The only recent European study in which the events of puberty have been followed longitudinally is the Harpenden Growth Study, which began 19 years ago in England and is still in progress. Anthropometric measurements have been taken, and the development of the breasts and pubic hair have been recorded photographically at 3monthly intervals throughout puberty. Though these data may be subject to certain biases, discussed below, they provide information available from no other source.

This paper describes the extent of normal individual variation observed in the events of puberty among the girls of the Harpenden Growth Study. We discuss: (a) variation in the chrono-

Received November 25, 1968. logical age at which adolescence begins and different stages of physical maturity are reached; (b) variation in the time taken to pass through the various stages of development of the breasts and of the pubic hair; (c) variation in the temporal relationships between the development of the breasts, of the pubic hair, the adolescent growth spurt, and menarche.

\section{Material and Methods}

The subjects were 192 white British girls participating in the Harpenden Growth Study. They had no physical abnormalities, and lived in family groups in a children's home where the standard of care was in all respects excellent. They came mainly from the lower socio-economic sector of the population, and some may not have received optimal physical care before entering the home (usually at ages 3 to 6 years). The reason for their admission was usually break-up of the parental home by divorce or by the death, illness, or desertion of one parent.

The subjects were seen at 3-monthly intervals during adolescence. Some were followed throughout their whole adolescent period; but some through part of it only.

The development of the secondary sex characters was studied in photographs taken in the nude at each examination. All the photographs of each girl were later examined together. By comparing each picture with the preceding one, changes in the breasts and pubic hair were readily recognized. The breasts and pubic hair on each photograph were classified into five stages of development, as described by Tanner (1962). These are illustrated in Fig. 1 and 2. All the ratings were made by the same observer (W.A.M.). The breast stages are as follows.

Stage 1: Pre-adolescent; elevation of papilla only.

Stage 2: Breast bud stage; elevation of breast and papilla as a small mound, enlargement of areola diameter.

Stage 3: Further enlargement of breast and areola, with no separation of their contours.

Stage 4: Projection of areola and papilla to form a secondary mound above the level of the breast.

Stage 5: Mature stage; projection of papilla only, due to recession of the areola to the general contour of the breast. 


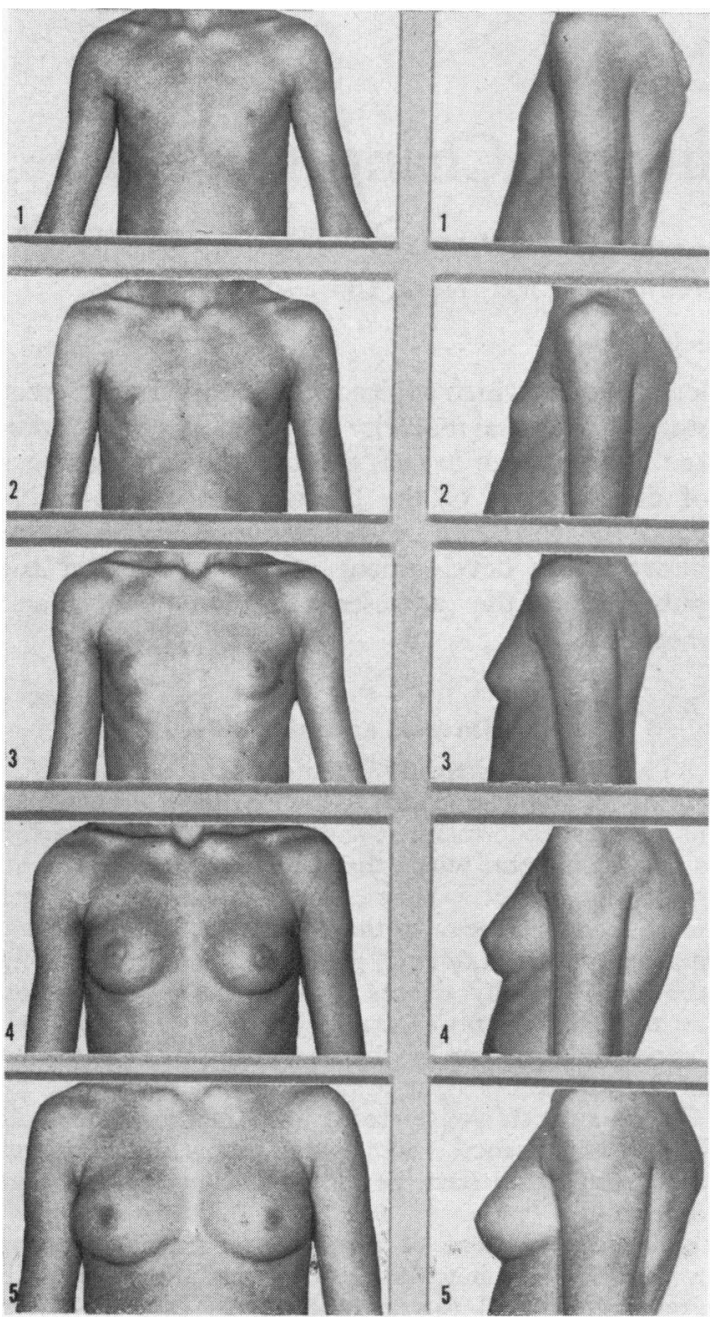

FIG. 1.-Standards for breast ratings. (From Tanner, 1969.)

The pubic hair stages are as follows:

Stage 1: Pre-adolescent; the vellus over the pubes is not further developed than that over the anterior abdominal wall, i.e. no pubic hair.

Stage 2. Sparse growth of long, slightly pigmented, downy hair, straight or only slightly curled, appearing chiefly along the labia. This stage is difficult to see on photographs, particularly of fair-haired subjects. Though Stage 2 rating was used in this study, it cannot be regarded as reliable, and the ages at which subjects are said to have reached Stage 2 are almost certainly too late.

Stage 3: Considerably darker, coarser, and more curled. The hair spreads sparsely over the junction of the pubes. This and subsequent stages were clearly recognizable on the photographs.
Stage 4: Hair is now adult in type, but the area covered by it is still considerably smaller than in most adults.

There is no spread to the medial surface of the thighs.

Stage 5: Adult in quantity and type, distributed as an inverse triangle of the classically feminine pattern. Spread to the medial surface of the thighs, but not up the linea alba or elsewhere above the base of the inverse triangle.

In about $10 \%$ of women the pubic hair spreads further after Stage 5 has been reached (Dupertuis, Atkinson, and Elftman, 1945), but this occurred in very few subjects in the present study; they were rated as Stage 5.

The girls were asked at each visit if they had begun to menstruate. If the reply was positive, they were asked in which of the 3 preceding months menarche had occurred, and the 15th day of that month was recorded as the date of menarche.

Each subject's stature was recorded at each visit. All measurements were taken by the same observer (R. H. Whitehouse), using the technique described by Marshall (1966). Using these measurements a growth velocity graph was plotted for each subject and a curve was fitted to the points by eye (see Tanner, Whitehouse, and Takaishi, 1966). The age at which the peak of this curve was reached was taken as the age at peak height velocity ('Instantaneous PHV').

Terminology. Throughout the text we have used abbreviations such as 'B3' to represent a point in time; in this case, the moment at which the change from breast Stage 2 to Stage 3 took place. The period of time during which the subject remains in Stage 3 is called the 'interval B3-B4.' B4 is the moment at which Stage 4 is reached. B2, B5, PH2, PH3, PH4, and PH5 similarly represent the moments at which the various stages of breast and pubic hair are reached. The 'interval B2-B5' represents the total time spent in Stages 2, 3, and 4, i.e. the entire duration of breast development.

Statistical methods. The data were 'mixed longitudinal', i.e. some individuals were followed continuously from the first sign of puberty to maturity, and some for only part of this period. Thus when we consider a single point in development, e.g. B4, some subjects would have been seen only before this point, and some only after it, while some would have been seen both before and after. It is unlikely that the exact moment of B4 would ever be observed; it is only certain that it occurred between two successive examinations of a given subject. Some authors (e.g. Deming, 1957) have assumed that a change from one stage to another took place when the subject was first seen to be in the later stage. As they examined their subjects at 6-monthly intervals, this estimate could be biased by up to 6 months for any individual. Other authors (Nicholson and Hanley, 1953) have assumed that a stage was reached at the mid-point of the interval between the last examination before and the first examination after subjects had reached this stage. 


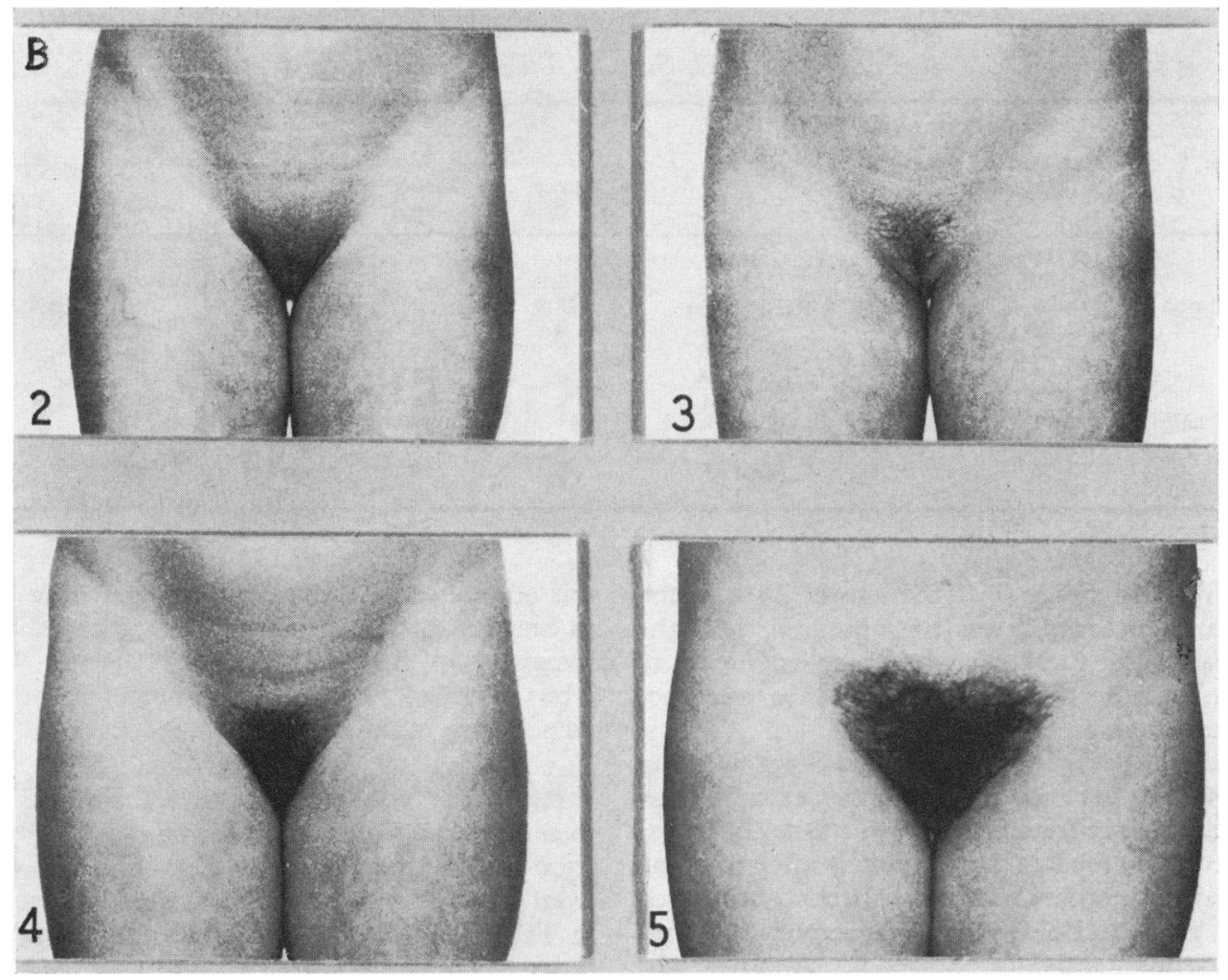

FIG. 2.-Standards for pubic hair ratings. (From Tanner, 1969.)

Yet others (e.g. Reynolds and Wines, 1948) do not state clearly how they made their estimates. But even interpolation between the ages of each individual at the examinations before and after reaching a given stage fails to give the best estimate of the population mean and standard deviation when mixed longitudinal data are available.

The best method (Swan, 1969) is one that gives maximum likelihood estimates of these statistics, making full and appropriate use of the information provided by those subjects who were seen only before or only after a given event, as well as by subjects seen both before and after. This method was therefore used in the analyses of our data.

For each calculation, the 192 subjects were divided into the following groups:

(1) Exactly specified: The age at which the stage was reached was known exactly. This applies only to menarche, but the estimated age of peak-height velocity (PHV) was also treated as an exactly specified observation.

(2) Lower bound: The stage was known to have been reached after a certain age, i.e. the subject left the study before reaching it.

(3) Upper bound: The stage was known to have been reached before a certain age, i.e. the subject had reached it before joining the study.

(4) Confined: The stage was reached within a known interval, i.e. between two examinations.

Subjects who gave no useful information in a given analysis were classified as 'missing'.

\section{Results}

Individual variation in sequence of events. In all girls the pubic hair passed from one stage to the next in sequence. No stages were omitted and there were no reversions to an earlier stage after a later one had been reached.

The same was true of breast Stages 1, 2, and 3, but 4 girls returned to Stage 4 after they had reached Stage 5 . The change from Stage 4 to 5 was observed in 57 girls, 20 of whom were subsequently followed for more than 2 years after reaching B5. 3 of them were rated as Stage 5 on one occasion but returned to Stage 4 for the remainder of their stay in the study, which was 2 years for 2 of them and 1 year for the other. One girl was rated Stage 4 at the age of 15 years, 
TABLE I

Age at Which Each Stage of Puberty was Reached

\begin{tabular}{|c|c|c|c|c|c|c|c|c|}
\hline \multirow{2}{*}{ Stage } & \multirow{2}{*}{ Mean (yr.) } & \multirow{2}{*}{ SD } & \multirow{2}{*}{ SE } & \multicolumn{5}{|c|}{ Number of Subjects $\star$} \\
\hline & & & & $\begin{array}{l}\text { Exactly } \\
\text { Specified }\end{array}$ & $\begin{array}{l}\text { Lower } \\
\text { Bound }\end{array}$ & $\begin{array}{l}\text { Upper } \\
\text { Bound }\end{array}$ & Confined & Missing \\
\hline $\begin{array}{l}\text { B2 } \\
\text { PH2^ } \\
\text { PHV (inst.) } \\
\text { B3 } \\
\text { PH3 } \\
\text { PH4 } \\
\text { B4 } \\
\text { Menarche } \\
\text { PH5 } \\
\text { B5 }\end{array}$ & $\begin{array}{l}11 \cdot 15 \\
11 \cdot 69 \\
12 \cdot 14 \\
12 \cdot 15 \\
12 \cdot 36 \\
12 \cdot 95 \\
13 \cdot 11 \\
13 \cdot 47 \\
14 \cdot 41 \\
15 \cdot 33\end{array}$ & $\begin{array}{l}1 \cdot 10 \\
1 \cdot 21 \\
0 \cdot 88 \\
1 \cdot 09 \\
1 \cdot 10 \\
1 \cdot 06 \\
1 \cdot 15 \\
1 \cdot 02 \\
1 \cdot 12 \\
1 \cdot 74\end{array}$ & $\begin{array}{l}0 \cdot 10 \\
0 \cdot 11 \\
0 \cdot 14 \\
0 \cdot 10 \\
0 \cdot 10 \\
0 \cdot 10 \\
0 \cdot 11 \\
0 \cdot 10 \\
0 \cdot 11 \\
0 \cdot 19\end{array}$ & $\begin{array}{r}0 \\
0 \\
39 \\
0 \\
0 \\
0 \\
0 \\
91 \\
0 \\
0\end{array}$ & $\begin{array}{r}41 \\
51 \\
0 \\
58 \\
59 \\
70 \\
70 \\
77 \\
101 \\
119\end{array}$ & $\begin{array}{r}51 \\
44 \\
0 \\
38 \\
39 \\
26 \\
27 \\
4 \\
11 \\
6\end{array}$ & $\begin{array}{r}97 \\
94 \\
0 \\
93 \\
91 \\
93 \\
92 \\
1 \\
77 \\
64\end{array}$ & $\begin{array}{r}3 \\
3 \\
153 \\
3 \\
3 \\
3 \\
3 \\
19 \\
3 \\
3\end{array}$ \\
\hline
\end{tabular}

$\star$ See text.

having reached Stage 5 at the age of $14 \cdot 4$ years. Her return to Stage 5 was not observed. All the photographs of these girls were re-examined to confirm that the changes in appearance were not due to errors in rating.

Three girls passed from Stage 3 to Stage 5 during the 3 months between 2 consecutive examinations and were never rated Stage 4. One of these withdrew from the study immediately after reaching Stage 5. The other 2 were subsequently followed for 3.8 years and 5.0 years, respectively, and remained consistently in Stage 5. Another girl

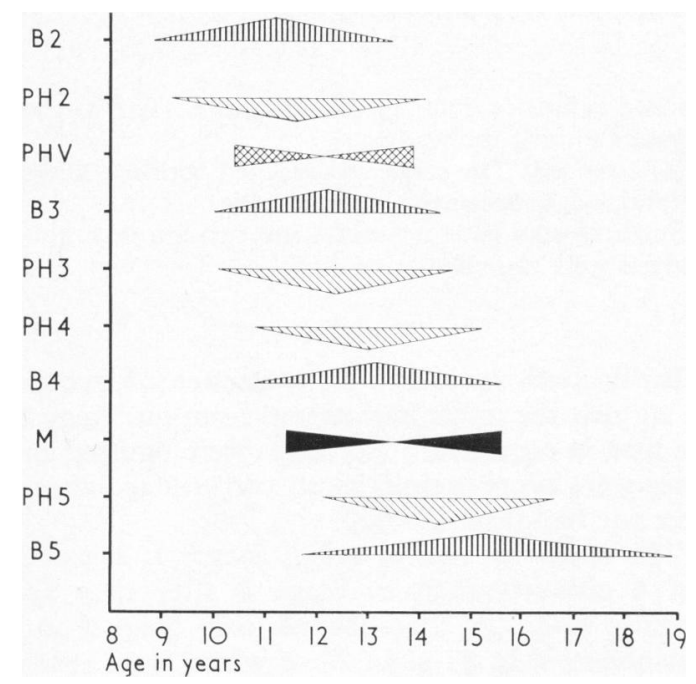

Fig. 3.-Age on reaching each stage of puberty, i.e. of breast $(B)$, pubic hair $(P H)$, menarche $(M)$, and peak height velocity $(P H V)$. The centre of each symbol represents the mean, and the length of the symbol is equivalent to two standard deviations on either side of the mean. (Based on the data in Table I.) missed one examination and changed from Stage 3 to Stage 5 during the intervening 6 months. She remained in Stage 5 for the following 4 years. Thus 4 out of 57 girls (7\%) apparently missed or passed very rapidly through Stage 4 .

Age on reaching stages. The estimated mean ages at which the various stages of puberty were reached, together with the number of subjects from which the means were estimated, are shown in Table I. The means are listed in chronological order. The figures for PH2 must be treated with reserve as the first appearance of pubic hair cannot readily be seen on photographs. The mean given in the Table is therefore almost certainly too high and the standard deviation is probably too large. PH5 has a larger standard deviation than any of the other ratings of pubic hair development. Though the recognition of this stage is slightly less exact than that of Stages 3 and 4 , the large standard deviation can be taken as a true reflection of the greater variation in the age at which this stage is reached. The figures for the age on reaching PHV are based on only 39 cases, but the standard deviation is the lowest in the Table. Fig. 3 indicates diagrammatically the wide variety in stages of development present among girls at every year of chronological age from 10 to 15 .

Variation in duration of stages. Table II shows the means and standard deviations of the intervals from the first sign of breast development (the point B2) to the first appearance of other stages of puberty (B3, $\mathrm{PH} 3$ etc.). These estimates were based on lower bound, upper bound, and confined data as shown in the Table, it being assumed that the data were normally distributed.

Fig. 4 and 5 show the actual distribution of the 
TABLE II

Lengths of Intervals (in years) from Beginning of Breast Development (B2) to Times of Reaching Other Stages

\begin{tabular}{|c|c|c|c|c|c|c|c|}
\hline \multirow{2}{*}{ Interval } & \multirow{2}{*}{$\begin{array}{c}\text { Mean } \\
(y r .)\end{array}$} & \multirow{2}{*}{ SD } & \multirow{2}{*}{ SE } & \multicolumn{4}{|c|}{ Number of Subjects } \\
\hline & & & & $\begin{array}{c}\text { Exactly } \\
\text { Specified }\end{array}$ & $\begin{array}{l}\text { Lower } \\
\text { Bound }\end{array}$ & $\begin{array}{l}\text { Upper } \\
\text { Bound }\end{array}$ & Confined \\
\hline $\begin{array}{l}\text { B2-B3 } \\
\text { B2-B4 } \\
\text { B2-B5 } \\
\text { B2-PH2 } \\
\text { B2-PH3 } \\
\text { B2-PH4 } \\
\text { B2-PH5 } \\
\text { B2-menarche } \\
\text { B2-PHV^ }\end{array}$ & $\begin{array}{l}0.93 \\
1.96 \\
4.46 \\
0.50 \\
1.81 \\
1.70 \\
3.09 \\
2.34 \\
1.01\end{array}$ & $\begin{array}{l}0.48 \\
0.93 \\
2.04 \\
0.87 \\
0.79 \\
0.78 \\
1.04 \\
1.03 \\
0.77\end{array}$ & $\begin{array}{l}0.06 \\
0.11 \\
0.27 \\
0.09 \\
0.09 \\
0.09 \\
0.13 \\
0.12 \\
0.12\end{array}$ & $\begin{array}{l}0 \\
0 \\
0 \\
0 \\
0 \\
0 \\
0 \\
0 \\
0\end{array}$ & $\begin{array}{r}26 \\
45 \\
95 \\
17 \\
28 \\
46 \\
76 \\
59 \\
0\end{array}$ & $\begin{array}{l}0 \\
0 \\
0 \\
3 \\
1 \\
0 \\
0 \\
0 \\
0\end{array}$ & $\begin{array}{l}84 \\
76 \\
47 \\
87 \\
81 \\
76 \\
61 \\
69 \\
45\end{array}$ \\
\hline
\end{tabular}

* Treated as a 'confined' observation, being assumed to have occurred at the mid-point of the year in which it was reached. This approach is more practicable in clinical work, and allowed more subjects to be employed in the present calculation than the use of 'instantaneous PHV'.

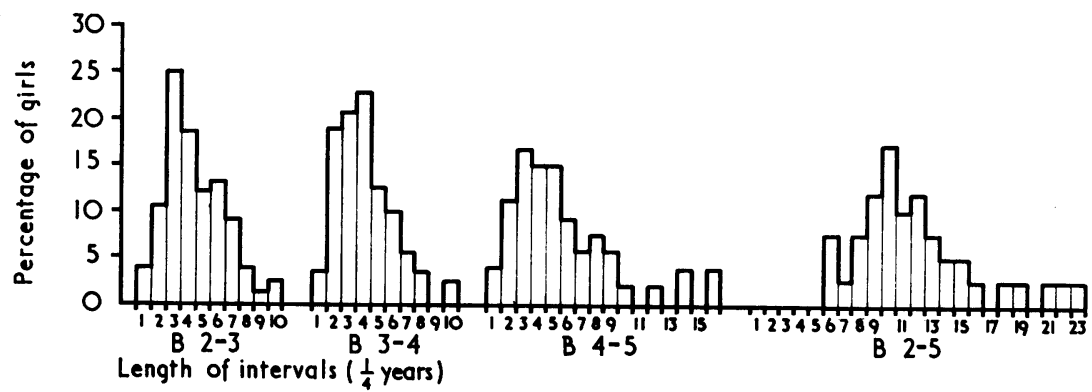

Fig. 4.-Distribution of intervals between stages of breast development.

lengths of each of the breast and pubic hair stages (e.g. breast Stage 3) in those girls who were seen before and after both the change from the stage before (i.e. from breast 2) and the change on to the next stage (i.e. to breast 4). Stage 3, for example, was assumed to have begun at the mid-point between the age at which the girl was last seen in Stage 2 and the age at which she was first seen in Stage 3. Stage 3 was assumed to have ended at the mid-point between the last age she was seen in Stage 3 and the first age she was seen in Stage 4.

The figures suggest that a log normal distribution

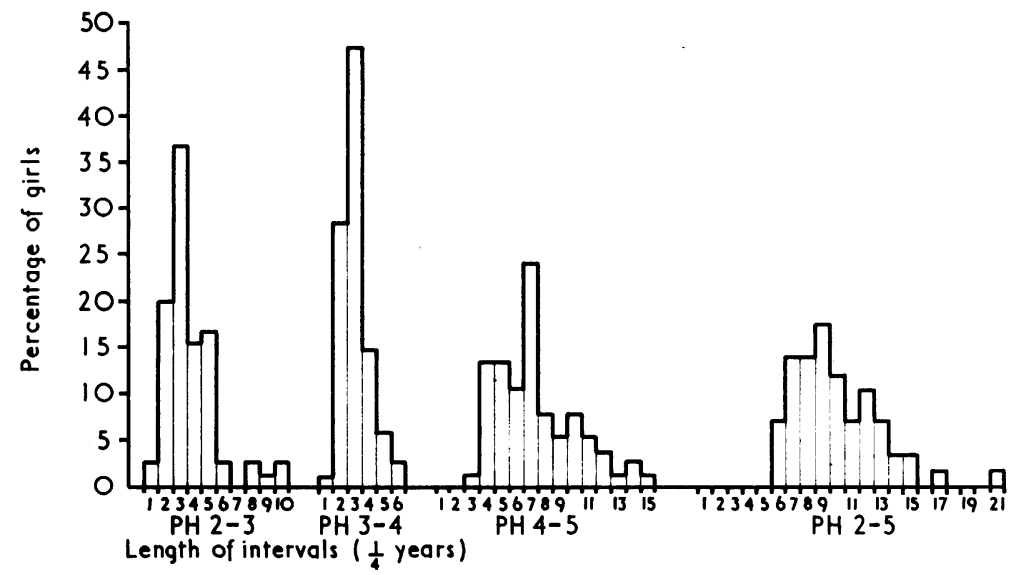

Fig. 5.-Distribution of intervals between stages of pubic hair development. 
TABLE III

Means and Centiles of Lengths of Intervals Calculated on Assumption of Log Normal Distribution

\begin{tabular}{|c|c|c|c|}
\hline Interval & $\begin{array}{c}\text { 95th } \\
\text { Centile }\end{array}$ & $\begin{array}{c}\text { Mean } \\
(\mathrm{yr} .)\end{array}$ & $\begin{array}{c}5 \text { th } \\
\text { Centile }\end{array}$ \\
\hline $\begin{array}{l}\text { B2-B3 } \\
\text { B3-B4 } \\
\text { B4-B5 } \\
\text { B2-B4 } \\
\text { B3-B5 } \\
\text { B2-B5 }\end{array}$ & $\begin{array}{l}1 \cdot 03 \\
2 \cdot 19 \\
6 \cdot 82 \\
3 \cdot 63 \\
7 \cdot 55 \\
8 \cdot 99\end{array}$ & $\begin{array}{l}0 \cdot 86 \\
0 \cdot 89 \\
1 \cdot 96 \\
1 \cdot 80 \\
3 \cdot 08 \\
4 \cdot 00\end{array}$ & $\begin{array}{l}0 \cdot 21 \\
0 \cdot 13 \\
0 \cdot 12 \\
0 \cdot 69 \\
0 \cdot 95 \\
1 \cdot 51\end{array}$ \\
\hline $\begin{array}{l}\text { PH2-PH3 } \\
\text { PH3-PH4 } \\
\text { PH4-PH5 } \\
\text { PH2-PH4 } \\
\text { PH3-PH5 } \\
\text { PH2-PH5 }\end{array}$ & $\begin{array}{l}1 \cdot 27 \\
0 \cdot 93 \\
2 \cdot 37 \\
2 \cdot 04 \\
3 \cdot 85 \\
3 \cdot 10\end{array}$ & $\begin{array}{l}0 \cdot 62 \\
0 \cdot 51 \\
1 \cdot 30 \\
1 \cdot 13 \\
1 \cdot 85 \\
2 \cdot 49\end{array}$ & $\begin{array}{l}0 \cdot 16 \\
0 \cdot 18 \\
0 \cdot 57 \\
0 \cdot 50 \\
0 \cdot 94 \\
1 \cdot 39\end{array}$ \\
\hline
\end{tabular}

might more properly describe the population as a whole, and that the standard deviation is not an adequate guide to the range of variation. The mean values of the intervals between the stages were therefore recalculated, together with the 5 th and 95th centiles, using the logarithms of the original data. The results are shown in Table III.

The mean intervals in Tables II and III are not identical with the differences between the mean ages at which each of the stages is reached, given in Table I. This is because the two estimates are based on slightly different samples. The mean interval may be a little biased by selective elimination of girls with longer intervals, a point discussed below.

Since the data are longitudinal, it is possible to see whether a girl who passes rapidly through one stage of development continues to pass rapidly through subsequent stages. The regression coefficient of the interval B3-B4 (duration of Stage B3) on the interval B2-B3 (duration of Stage B2) was $0.35 \pm 0.15$, and the regression of the interval $\mathrm{B} 2-\mathrm{B} 4$ on $\mathrm{B} 2-\mathrm{B} 3$ was $1 \cdot 32 \pm 0 \cdot 15$. However, the regression of B4-B5 on B2-B3 was insignificantly different from zero. Thus if the breasts start developing slowly they usually go on doing so up to B4, but the time spent in Stage 4 is not related to the duration of the earlier stages. Possibly the dissociation represents a difference between oestrogen stimulation and stimulation by a mammogenic hormone.

Interrelationships between events. The girls were not all in the same stage of breast development when they reached a given stage of pubic hair development. Similarly when they reached a given breast stage they were in different stages for pubic hair. Peak height velocity and menarche were also reached during different stages of breast or pubic hair development in different girls.

Table IV shows the percentage of girls in each stage of breast development when they were first seen in each successive $\mathrm{PH}$ stage. The table reads as follows. The first appearance of pubic hair Stage 2 was observed in 88 girls, the first appearance of Stage 3 in 93 girls, of Stage 4 in 102 girls, and of Stage 5 in 80 girls. The material is mixed longitudinal; thus most but not all of the 88 girls reaching Stage 2 are included in the 102 reaching Stage 4 . Of the 88 girls seen on reaching pubic hair Stage 2, 14 (or $16 \%$ ) were in breast Stage 1, $43(49 \%)$ in breast Stage 2, and so on. It is noteworthy that 3 girls who had reached pubic hair Stage 3 were still without breast development, and 2 girls had even reached pubic hair Stage 4 without breast development. Breast Stage 3 was seen at all stages of pubic hair development, but breast Stage 5 did not occur at pubic hair Stage 2 , and was present in only 1 girl at pubic hair Stage 3.

Table $\mathrm{V}$ is similarly constructed, and gives the number of girls in each stage of pubic hair development when reaching successive breast stages. $61 \%$ of the girls were without photographically

TABLE IV

Number and Percentage of Girls in Each Stage of Breast Development on Reaching Each Stage of Pubic Hair Development (i.e. at PH2, PH3, etc.)

\begin{tabular}{|c|c|c|c|c|c|c|c|c|c|c|c|}
\hline & \multicolumn{10}{|c|}{ Breast Stage } & \multirow{3}{*}{$\begin{array}{l}\text { No. of Girls } \\
\text { Rated }\end{array}$} \\
\hline & \multicolumn{2}{|c|}{1} & \multicolumn{2}{|c|}{2} & \multicolumn{2}{|c|}{3} & \multicolumn{2}{|c|}{4} & \multicolumn{2}{|c|}{5} & \\
\hline & No. & $\%$ & No. & $\%$ & No. & $\%$ & No. & $\%$ & No. & $\%$ & \\
\hline $\begin{array}{l}\text { PH2 } \\
\text { PH3 } \\
\text { PH4 } \\
\text { PH5 }\end{array}$ & $\begin{array}{r}14 \\
3 \\
2 \\
0\end{array}$ & $\begin{array}{r}16 \\
3 \\
2 \\
0\end{array}$ & $\begin{array}{r}43 \\
21 \\
4 \\
1\end{array}$ & $\begin{array}{r}49 \\
23 \\
4 \\
1\end{array}$ & $\begin{array}{r}24 \\
46 \\
44 \\
9\end{array}$ & $\begin{array}{l}27 \\
50 \\
43 \\
11\end{array}$ & $\begin{array}{r}7 \\
22 \\
46 \\
39\end{array}$ & $\begin{array}{r}8 \\
24 \\
45 \\
49\end{array}$ & $\begin{array}{r}0 \\
1 \\
6 \\
31\end{array}$ & $\begin{array}{r}0 \\
1 \\
6 \\
39\end{array}$ & $\begin{array}{r}88 \\
93 \\
102 \\
80\end{array}$ \\
\hline
\end{tabular}


TABLE V

Number and Percentage of Girls in Each Stage of Pubic Hair Development on Reaching Each Stage of Breast Development (i.e. at B2, B3, etc.)

\begin{tabular}{|c|c|c|c|c|c|c|c|c|c|c|c|}
\hline & \multicolumn{10}{|c|}{ PH Stage } & \multirow{3}{*}{$\begin{array}{l}\text { No. of Girls } \\
\text { Rated }\end{array}$} \\
\hline & \multicolumn{2}{|c|}{1} & \multicolumn{2}{|c|}{2} & \multicolumn{2}{|c|}{3} & \multicolumn{2}{|c|}{4} & \multicolumn{2}{|c|}{5} & \\
\hline & No. & $\%$ & No. & $\%$ & No. & $\%$ & No. & $\%$ & No. & $\%$ & \\
\hline $\begin{array}{l}\text { B2 } \\
\text { B3 } \\
\text { B4 } \\
\text { B5 }\end{array}$ & $\begin{array}{r}54 \\
21 \\
4 \\
0\end{array}$ & $\begin{array}{r}61 \\
22 \\
4 \\
0\end{array}$ & $\begin{array}{r}26 \\
26 \\
10 \\
1\end{array}$ & $\begin{array}{r}29 \\
28 \\
10 \\
2\end{array}$ & $\begin{array}{r}7 \\
31 \\
23 \\
4\end{array}$ & $\begin{array}{r}8 \\
33 \\
24 \\
7\end{array}$ & $\begin{array}{r}2 \\
15 \\
49 \\
22\end{array}$ & $\begin{array}{r}2 \\
16 \\
51 \\
36\end{array}$ & $\begin{array}{r}0 \\
1 \\
11 \\
34\end{array}$ & $\begin{array}{r}0 \\
1 \\
11 \\
56\end{array}$ & $\begin{array}{l}89 \\
94 \\
97 \\
61\end{array}$ \\
\hline
\end{tabular}

visible pubic hair when they began breast development, and $22 \%$ were without it when they reached breast Stage 3. However these percentages might have been lower if the pubic hair ratings had been made from clinical observation of the subjects rather than from photographs. At reaching breast Stage 3, 28\% of girls are in pubic hair Stage 2, $33 \%$ in pubic hair Stage 3 , and $16 \%$ in pubic hair Stage 4. There are no girls of breast Stage 5 without some degree of development of pubic hair, and only $9 \%$ who are less than pubic hair Stage 4.

Fig. 6 shows cumulative percentages of the girls who had reached each pubic hair stage by the time they had reached each breast stage.

Tables VI and VII show the percentage of girls

TABLE VI

Number and Percentage of Girls in Each Stage of Breast and Pubic Hair Development at Instantaneous PHV

\begin{tabular}{|c|c|c|c|c|c|c|c|c|c|c|c|}
\hline & \multicolumn{10}{|c|}{ Breast Stage } & \multirow{3}{*}{ No. of Girls } \\
\hline & \multicolumn{2}{|c|}{1} & \multicolumn{2}{|c|}{2} & \multicolumn{2}{|c|}{3} & \multicolumn{2}{|c|}{4} & \multicolumn{2}{|c|}{5} & \\
\hline & No. & $\%$ & No. & $\%$ & No. & $\%$ & No. & $\%$ & No. & $\%$ & \\
\hline \multirow[t]{4}{*}{ PHV } & 0 & 0 & 10 & 26 & 20 & 51 & 9 & 23 & 0 & 0 & 39 \\
\hline & \multicolumn{10}{|c|}{ PH Stage } & \\
\hline & \multicolumn{2}{|c|}{1} & \multicolumn{2}{|c|}{2} & \multicolumn{2}{|c|}{3} & \multicolumn{2}{|c|}{4} & \multicolumn{2}{|c|}{5} & \\
\hline & No. & $\%$ & No. & $\%$ & No. & $\%$ & No. & $\%$ & No. & $\%$ & \\
\hline PHV & 9 & 23 & 11 & 28 & 14 & 36 & 5 & 13 & 0 & 0 & 39 \\
\hline
\end{tabular}

TABLE VII

Number and Percentage of Girls in Each Stage of Breast and Pubic Hair Development at Menarche

\begin{tabular}{|c|c|c|c|c|c|c|c|c|c|c|c|}
\hline & \multicolumn{10}{|c|}{ Breast Stage } & \multirow{3}{*}{ No. of Girls } \\
\hline & \multicolumn{2}{|c|}{1} & \multicolumn{2}{|c|}{2} & \multicolumn{2}{|c|}{3} & \multicolumn{2}{|c|}{4} & \multicolumn{2}{|c|}{5} & \\
\hline & No. & $\%$ & No. & $\%$ & No. & $\%$ & No. & $\%$ & No. & $\%$ & \\
\hline \multirow[t]{4}{*}{ Menarche } & 0 & 0 & 1 & 1 & 21 & 26 & 50 & 62 & 9 & 11 & 81 \\
\hline & \multicolumn{10}{|c|}{ PH Stage } & \\
\hline & \multicolumn{2}{|c|}{1} & \multicolumn{2}{|c|}{2} & \multicolumn{2}{|c|}{3} & \multicolumn{2}{|c|}{4} & \multicolumn{2}{|c|}{5} & \\
\hline & No. & $\%$ & No. & $\%$ & No. & $\%$ & No. & $\%$ & No. & $\%$ & \\
\hline Menarche & 1 & 1 & 3 & 4 & 15 & 19 & 50 & 63 & 11 & 14 & 80 \\
\hline
\end{tabular}




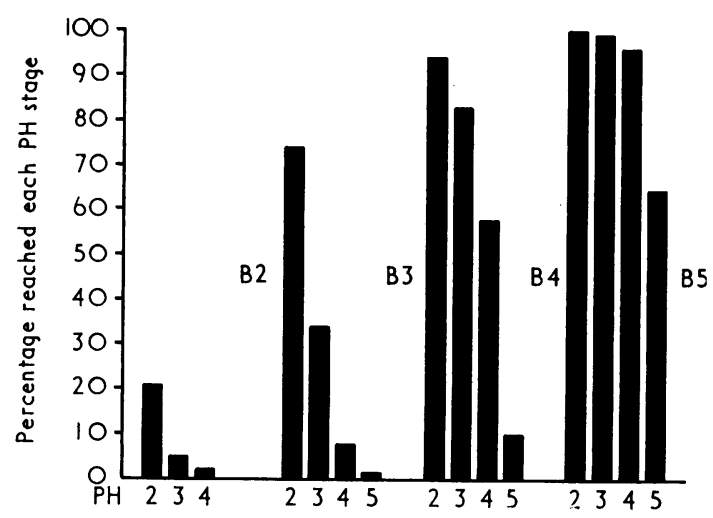

Fig. 6.-Percentage of girls who had reached each stage of pubic hair development before reaching each stage of breast development. B2, B3 etc. represent the moments of reaching the corresponding breast stages. Thus the histogram between $B 2$ and B3 shows the percentage of girls in breast Stage 2, who reached each pubic hair stage before they reached the 3 rd breast stage.

in each stage of breast and pubic hair development when peak PHV and menarche were reached. Cumulative percentages of girls who had reached menarche and PHV by each stage of breast development are illustrated in Fig. 7. For the purposes of this diagram, however, age at PHV was taken as the mid-point of the year in which the average rate of growth was maximal. This method of estimation is much more convenient for clinical purposes, but it does not give precisely the same relation between PHV and breast development as is given by the more exact estimation of instantaneous PHV used in Table VI. The percentages having reached PHV in the diagram are based on 45 subjects.

All the girls in whom we detected the peak of the height spurt (instantaneous PHV) had reached this point before the breasts or pubic hair were adult. Nearly a quarter of them had passed their maximum rate of growth before their pubic hair became visible on photographs. PHV was reached during breast Stage 2 in $26 \%$. We have no evidence that PHV was reached in any girl before her breasts began to develop, but this may have happened as age at instantaneous PHV was known for only 39 of the subjects.

Just over $10 \%$ of the subjects had adult secondary sex characters before they began to menstruate, but menarche occurred during breast Stage 3 in $25 \%$ of girls and during breast Stage 4 in $60 \%$. One girl began to menstruate at the age of 12.5 but her pubic hair did not become visible until she was aged 13.4, though she had developed breast buds

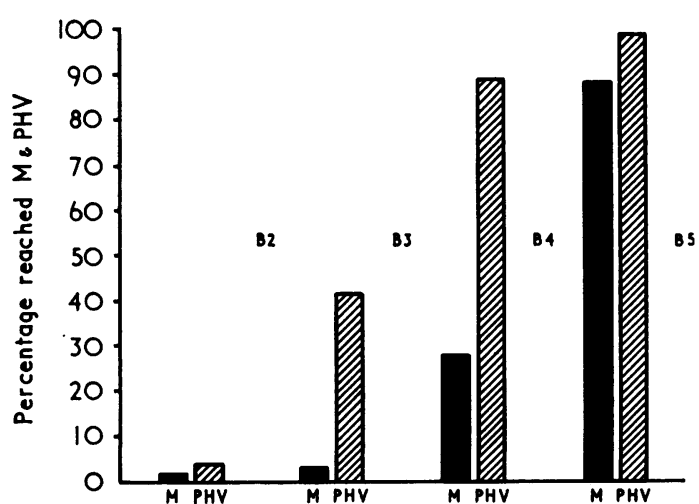

FIG. 7.-Percentage of girls who had reached menarche and peak height velocity before reaching each stage of breast development (see caption for Fig. 6). PHV was taken as the mid-point of the year in which growth rate was maximal (45 subjects). Note the slightly different result obtained by using 'Instantaneous PHV' (Table VI).

at $11 \cdot 6$. Her subsequent development was apparently quite normal.

Menarche occurred after PHV in all subjects for whom both dates were known. The correlation coefficient between age at menarche and age at PHV was 0.91 , between age at B2 and age at PHV 0.82 , and between $B 2$ and menarche 0.64 .

Influence of age on length of intervals. It is interesting to inquire if children who reach puberty late tend to pass through it more quickly or more slowly than those who begin earlier.

The beginning of breast development (B2) and menarche are the two events whose dates can be most reliably determined. One occurs early and the other late in puberty, so the difference between the ages at which they happen is a convenient measure of the over-all time taken for puberty. The correlation coefficient of the age midway between these points with the interval between them was 0.17 (63 pairs of observations), which is not significantly different from zero. Thus the interval between the two events does not appear to be related to the age at which they take place. The correlation coefficient between the mid-point. of the interval B2-PH3 and the length of the interval was also insignificant $(-0 \cdot 11 ; 78$ pairs of observations).

Another way of describing the relation between the ages at which two stages are reached is by the regression of one age upon the other. For statistical reasons (see Healy et al., 1969), the regression technique is not appropriate for testing the hypo- 
thesis that pubertal changes occur more quickly in the early-maturing, and if it is used in this way seemingly contradictory results appear. However, it has a clinical use in prediction. For example the regression of age at menarche on age at $\mathbf{B} 2$ can be used to give the normal limits of time within which menarche should occur after B2 has first been observed. The regression equation is as follows.

Age at menarche $=13.46+0.46$ (age at B2$11 \cdot 17)$. This gives the average prediction for a given subject, and the $95 \%$ confidence limits within which the subject's age at menarche should lie are \pm 1.9 years around this average prediction. Similar equations for other relationships can be found in Healy et al. (1969).

\section{Discussion}

Validity and reliability of observations. Our sample of girls is not representative of the British population. Most of them had poor socio-economic backgrounds and had lived in unsatisfactory home conditions before entering the home, where they were studied. They were, nevertheless, in excellent physical health, well fed, and their growth in stature was well within normal limits. They reached menarche, on the average, about 4 months later than the population of London.

Girls joined and left the study at different ages, but there is no evidence that their coming or going was in any way related to their sexual maturation. The statistical techniques which were used allowed for the fact that many subjects were lost to observation between the ages of 15 and 16. The bias attributable to this cause should therefore be slight.

Consistency of rating was ensured by comparing all the photographs of each girl with one another. Ratings could then be given with knowledge of the complete development of the child. Thus, for example, a girl with large breasts at Stage 3 would not be erroneously rated as 5 , and Stage 5 in a girl with small breasts would not be rated as 3 . These errors are common when ratings are made at clinical examination, though they can be minimized if the ratings are recorded and taken into account at subsequent examinations. Re-ratings of the photographs by the same observer gave only occasional differences of one photograph ( 3 months) in the age at which ratings changed from one stage to the next. These differences showed no bias in either direction.

Pubic hair was not seen on the photograph until some time after it had appeared on the body. The estimated mean age of reaching $\mathrm{PH} 2$ is there- fore later than the true one, and the interval from PH2 to later events is underestimated. The change from Stage 2 to Stage 3 and subsequent changes could be readily recognized in the photographs.

All the breast stages could be easily recognized. The value of using Stage 4 has been questioned by some authors (see Tanner, 1962, p. 37), but it does seem to be a condition in which most girls remain consistently for a period of time before passing on to the mature stage. The proportion of girls who either omit Stage 4 (7\% in these data), or fail to progress beyond it, appears to be small (our data do not provide an estimate of the latter percentage). An appearance similar to Stage 4 can apparently arise in a small number of girls after they had reached Stage 5, but this is unusual.

Interpretation of results. The data presented are relevant to the following clinical questions.

Question 1. Is a patient's pubertal development within normal limits for her age ?

This can easily be answered if the patient has begun to menstruate, for the normal age limits are fairly well documented. If she has not begun to menstruate, however, her developmental status must be compared with the range of ages within which different stages of sexual maturation are normally reached (see Table I). The mean age of menarche in our sample is approximately 0.3 years ( 4 months) later than that given by Scott (1961) for a large sample of London children. It is probably justifiable to assume that our figures, with an adjustment of 0.3 years to each mean, would represent the current London population within reasonable limits of accuracy. The same argument can be applied to other populations, provided the intervals between the mean ages at which the various stages are reached could be assumed to be similar to ours.

In a cross-sectional study of 662 London girls (Hogben, Waterhouse, and Hogben, 1948), the interval from B2 to B5 (each estimated by probits) was 4.8 years, as compared with our interval of $4 \cdot 2$ years. The mean duration of pubic hair development was $2 \cdot 7$ years in our sample and $1 \cdot 9$ years according to Hogben et al., but they may have judged the mature stage by different criteria. We do not know if the differences between the two samples are statistically significant, as Hogben's data are cross-sectional, and therefore the standard errors of the mean intervals could not be determined.

The interval from the mean age at B2 to the mean age of menarche in Hogben's sample was 
Marshall and Tanner

TABLE VIII

Mean Ages for Development Points in 4 Studies

\begin{tabular}{|c|c|c|c|c|c|c|c|c|c|c|}
\hline Author & $\begin{array}{l}\text { Social } \\
\text { Class }\end{array}$ & B2 & B3 & B4 & B5 & PH2 & PH3 & PH4 & PH5 & Menarche \\
\hline $\begin{array}{l}\text { Reynolds and Wines } \\
\quad(1948)\end{array}$ & $\begin{array}{l}\text { Upper- } \\
\text { Middle }\end{array}$ & $10 \cdot 8$ & $11 \cdot 4$ & $12 \cdot 2$ & $13 \cdot 7$ & $11 \cdot 0$ & $11 \cdot 9$ & $12 \cdot 5$ & $13 \cdot 9$ & $12 \cdot 9$ \\
\hline $\begin{array}{l}\text { Nicholson and Hanley } \\
\text { (1953) }\end{array}$ & $\begin{array}{l}\text { Upper- } \\
\text { Middle }\end{array}$ & $10 \cdot 6$ & $11 \cdot 2$ & - & $13 \cdot 9$ & $11 \cdot 6$ & $12 \cdot 5$ & $13 \cdot 2$ & - & $12 \cdot 8$ \\
\hline $\begin{array}{l}\text { Marshall and Tanner } \\
\text { (present paper) } \\
\text { Lee et al. (1963) }\end{array}$ & $\begin{array}{l}\text { Lower } \\
\text { Upper } \\
\text { Middle } \\
\text { Lower }\end{array}$ & $\begin{array}{r}11 \cdot 15 \\
9 \cdot 93 \\
10 \cdot 22 \\
10 \cdot 65\end{array}$ & $12 \cdot 15$ & $13 \cdot 11$ & $15 \cdot 33$ & $11 \cdot 69$ & $12 \cdot 36$ & $12 \cdot 95$ & $14 \cdot 41$ & $\begin{array}{l}13 \cdot 47 \\
12 \cdot 51 \\
12 \cdot 75 \\
13 \cdot 25\end{array}$ \\
\hline
\end{tabular}

$2 \cdot 5$ years, as compared with our interval of $2 \cdot 3$ years. Intervals of 2.0 to 2.5 years were also found in 49 middle-class white Midwestern Americans (Reynolds and Wines, 1948) and in a larger sample of Californian children whose parents' education was above average (Nicholson and Hanley, 1953). In both these American studies however, the mean interval from B2 to B5 (2.9 to 3.3 years) was about a year less than the estimated value for our population. This discrepancy may be partly due to their interpreting the rating criteria differently or to their different methods of statistical analysis. Data from the American and other studies are summarized in Table VIII. (Nicholson and Hanley did not record a stage comparable with our breast Stage 4. Their Stage 4 is apparently equivalent to our Stage $\mathbf{5}$ and is recorded as such in this Table.)

All the reports in the literature give standard deviations of about 1 year for the age at which each stage of puberty is reached. The similarity of these standard deviations and of the interval from the beginning of breast development to menarche in all the reported studies is more striking than the differences between the various samples.

For practical purposes, therefore, the development of a girl's breasts can be regarded as normal if she reaches a given stage within 2 years on either side of the mean value for her population. This mean would be obtained by adjusting our means in Table I according to the local age of menarche. Marshall and Tanner (1968) have summarized the most recent information about the age of menarche in various parts of the world.

Our data on the development of the breasts, adjusted for age at menarche, may be applicable to some Asian communities as well. Lee, Chang, and Chan (1963) reported a cross-sectional study of 3278 Chinese girls in Hong Kong. The beginning of breast development in three social classes was advanced in comparison with our subjects (see Table VIII), and menarche was advanced by a similar amount. The average Chinese, however, did not begin to develop pubic hair until a few months before menarche, or about 2 years after the appearance of breast buds. It is not clear whether the delayed appearance of pubic hair is due to lack of sensitive hair follicles, delay in the production of androgens, or a lower concentration of androgens in the blood.

Question 2. Puberty having begun, are breasts and pubic hair developing at a normal rate?

Tables II and III give the mean intervals between different stages of development, together with estimates of the range of normal variation. Fig. 8, 9, and 10 also provide a diagrammatic basis for comparison of a child's rate of progress with that of the girls in our sample. These figures differ from the Tables in that they illustrate actual data and do not make any assumptions about their distribution. The figures do not take into account $7 \%$ of the girls in our study and $16 \%$ of the 49 girls studied by Reynolds and Wines, who either did not pass through breast Stage 4 at all or passed through it very quickly. It may be possible in the future to associate unusually long or short intervals between certain stages with specific abnormalities.

Girls who pass slowly through breast Stage 2 can be expected to pass slowly through Stage 3.

Question 3. Are the breast and pubic hair developing in unison and in correct relation to the growth spurt and menarche?

Our data suggest that it is not abnormal for the breasts to reach Stage 4 before pubic hair appears. Alternatively the pubic hair may occasionally reach Stage 3 or even 4 in normal girls before there is any development of the breasts. Menarche usually occurs during breast Stages 3 or 4 , but some normal girls do not menstruate until their breasts 


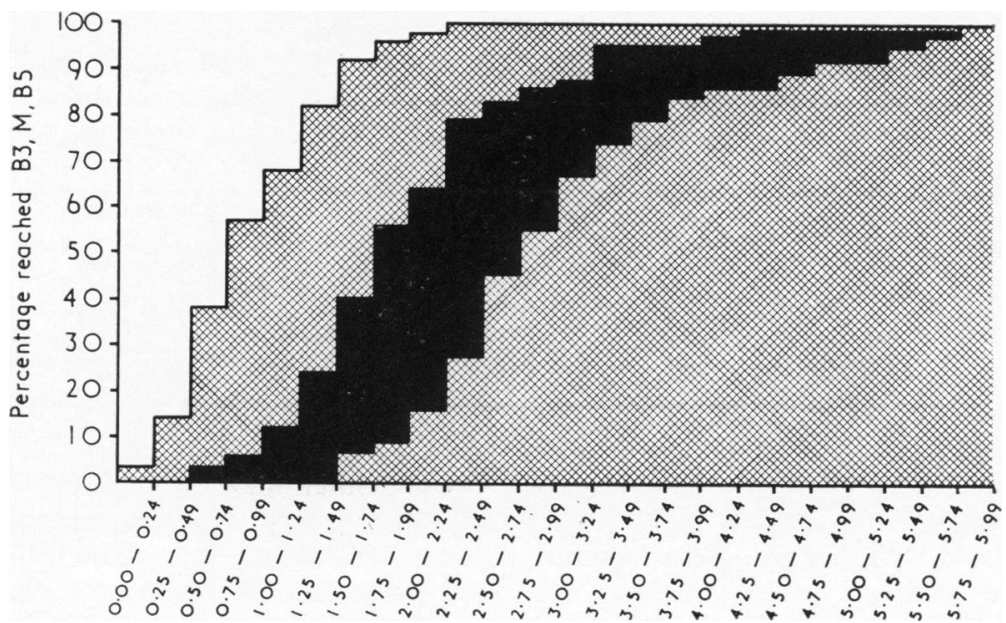

FIG. 8.-Accumulative percentages of girls who had reached B3 (left-hand columns), menarche (black columns), and B5 (right-hand columns), at given intervals, in years, after reaching B2.

are mature. More detailed information is given in Tables IV to VII and Fig. 6 and 7, which are in good agreement with data available from other authors.

Reynolds and Wines (1948) found that 18 out of 32 girls were in Stage 4 for both pubic hair and breasts when menarche occurred, though 1 girl was at Stage 1 for both, and menarche also occurred during other breast and pubic hair stages. Breast development began before pubic hair appeared in 26 girls. Pubic hair appeared first in 16 girls and, in 7, B2 and PH2 were almost simultaneous. B2 was

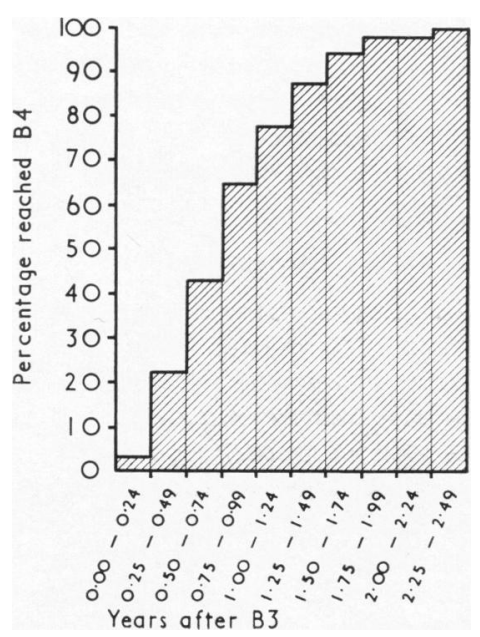

FIG. 9.-Accumulative percentages of girls who had reached B4 at given intervals, in years, after reaching B3. a year or more before $\mathrm{PH} 2$ in 15 girls, while $\mathrm{PH} 2$ was a year or more before B2 in 9 girls.

It is important to recognize that the relation between the different events of puberty is a more significant index of normality than the chronological age at which they occur. For example a 17-year-old girl who had not menstruated, but was growing rapidly and had breasts and pubic hair at Stage 3, could be regarded as an example of normal but late adolescence. Menarche would be expected in the near future (for examples see Tanner, 1969). If, on the other hand, breasts

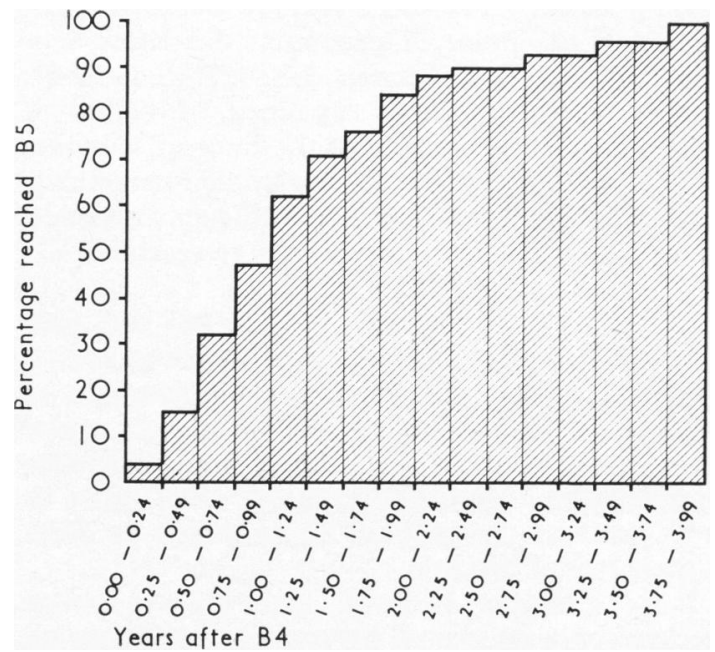

FIG. 10.-Accumulative percentages of girls who had reached B5 at given intervals, in years, after reaching B4. 
TABLE IX

Correlation Coefficients Between Ages at Reaching B2, PH2, Menarche, and PHV, According to Various Authors

\begin{tabular}{|c|c|c|c|c|c|c|}
\hline Author & $\begin{array}{l}\text { No. of } \\
\text { Subjects }\end{array}$ & B2-PH2 & B2-Menarche & PH2-Menarche & PHV-Menarche & B2-PHV \\
\hline $\begin{array}{l}\text { Shuttleworth (1939) } \\
\text { Reynolds and Wines } \\
\quad(1948)\end{array}$ & $\begin{array}{r}246 \\
49\end{array}$ & $\overline{0.66}$ & $\overline{0.86}$ & $\overline{0 \cdot 70}$ & $\underline{0.71}$ & - \\
\hline $\begin{array}{l}\text { Nicholson and Hanley } \\
(1953)\end{array}$ & 65-82 & $0 \cdot 75$ & $0 \cdot 74$ & $0 \cdot 74$ & $0 \cdot 71$ & 0.80 \\
\hline $\begin{array}{l}\text { Deming (1957) } \\
\text { Marshall and Tanner } \\
\quad(1968)\end{array}$ & $\begin{array}{c}24 \\
45-97\end{array}$ & - & $\overline{0.64}$ & - & $\begin{array}{l}0.93 \\
0.91\end{array}$ & $\begin{array}{l}0 \cdot 78 \\
0 \cdot 82\end{array}$ \\
\hline
\end{tabular}

and pubic hair had been mature for 2 or 3 years and growth had apparently ceased, the relation between events would be abnormal and a different explanation would have to be looked for. Yet other causes would have to be considered if there were no signs of puberty at all.

We cannot assume that a girl in early puberty is about to grow more quickly. Our data indicate that more than a quarter of girls reach the peak of their adolescent height spurts, and their growth begins to slow down, while the development of the breasts is in its earliest stage and before the pubic hair is visible photographically.

All the girls in this study, like those reported by previous authors, had passed the peak of their height spurt before menstruation began. 20 of the 24 girls studied by Deming (1957) had menarche within 6 months of the time when their growth was decelerating most rapidly. We can therefore confidently reassure the tall girl who has reached menarche at an early age that her growth is now slowing down. The close relation between menarche and the point of maximum deceleration of height growth (see Tanner, 1969, Fig. 1-30 for detail) cannot yet be explained. Possibly it reflects correlated changes in the rates of secretion of hormones or changes in their cyclic fluctuations. Table IX lists the correlation coefficients obtained by various authors between ages at reaching B2, $\mathrm{PH} 2, \mathrm{PHV}$, and menarche.

The view (e.g. Tanner, 1962, p. 94) that girls who reach puberty late, in terms of chronological age, tend to pass through the whole sequence of changes more slowly than those who began earlier is incorrect, and founded on a statistical misinterpretation. According to our data there is little tendency for early or late maturers to differ in their rate of passage.

It is generally believed that some common mechanism in the central nervous system adjusts the output of the pituitary hormones which activate both the adrenal cortices and the ovaries at puberty, though either may be activated independently in abnormal circumstances (premature thelarche or premature adrenarche). The fact that the breasts and pubic hair do not necessarily develop simultaneously, and that the relation between them in individual normal girls is variable, suggests that partially independent central mechanisms may be responsible for triggering these two aspects of development. Variations in the sensitivity of the skin to androgens may also be important.

The occurrence of maximal growth rate (PHV) near the beginning of puberty in some girls implies that their growth rate has been accelerated for a considerable time before signs of puberty appeared. If we assume that steroid hormones are responsible for the growth spurt, we must then conclude that, in some girls, the growth mechanism is more sensitive to these hormones than the breasts or the pubic hair follicles, while in other girls the reverse is true. Alternatively, we may implicate growth hormone in the initiation of the spurt. Increased production of growth hormone would be subject to a different mechanism from that which controls the steroid hormone output, and would not be expected to be too closely synchronized with the development of the breasts and pubic hair. For further discussion of this problem, see Tanner (1969).

\section{Summary}

Mixed longitudinal data on the physical changes at puberty in 192 normal girls are presented, together with pictorial standards for stages of breast and pubic hair development.

The first sign of puberty (i.e. either breast or pubic hair development) appeared between the ages of 8.5 years and 13 years in $95 \%$ of girls, and the breasts reached the mature stage between 11.8 and 18.9 years. The mean ages at which the intermediate stages of breast and pubic hair development were reached are given; all had standard deviations of approximately 1 year. 
The mean age at peak height velocity (i.e. the maximum rate of growth in stature) was $12 \cdot 14 \pm$ $\pm 0 \cdot 14(\mathrm{SD}=0 \cdot 88)$ and the mean age at menarche was $13 \cdot 47 \pm 0 \cdot 10(\mathrm{SD}=1 \cdot 02)$.

The limits of normal variation in the length of time which girls take to pass from one stage of breast or pubic hair development to another are given. The interval from the first sign of puberty to complete maturity varied from 1.5 years to over 6 years. The bud stage of breast development persisted for between 6 months and 2 years before further change took place. The mean interval from the beginning of breast development to menarche was $2 \cdot 3 \pm 0 \cdot 1$ years, but the range observed was 6 months to 5 years 9 months. The mean interval from the beginning of breast development to peak height velocity was $1.01 \pm 0.12$ years $(S D=$ $0 \cdot 77)$.

The limits of normal variation in the relation between breast and pubic hair development, the adolescent growth spurt, and menarche are described. Peak height velocity was reached very early in puberty by about $25 \%$ of girls, and in all cases it preceded menarche. $90 \%$ of girls had menstruated before their breasts reached the mature stage. Pubic hair was seen before breast development had begun in about a third of all girls.

The use of these data in making a clinical distinction between normal and abnormal puberty is discussed, together with their relevance to the study of the neuro-endocrine mechanisms by which puberty is controlled.

We are grateful to Dr. C. Asher for information about the occurrence of menarche in the subjects; to Mr. A. V. Swan for the more complex statistical analyses, to $\mathrm{Mr}$. R. $\mathrm{H}$. Whitehouse for repeated measurements of the girls' stature, and to Mr. M. J. R. Healy for advice on statistical matters. We also gratefully acknowledge financial support from the Medical Research Council and the Nuffield Foundation.

\section{REFERENCES}

Deming, J. (1957). Application of the Gompertz curve to the observed pattern of growth in length of 48 individual boys and girls during the adolescent cycle of growth. Hum. Biol., $29,83$.

Dupertuis, C. W., Atkinson, W. B., and Elftman, H. (1945). Sex differences in pubic hair distribution. ibid., 17, 137.

Healy, M. J. R., Swan, A., Marshall, W. A., and Tanner, J. M. (1969). The use of regression formulae in relating the age at one event during growth to a subsequent one. In preparation.

Hogben, H., Waterhouse, J. A. H., and Hogben, L. (1948). Studies on puberty. Part I. Brit. F. soc. med., 2, 29.

Lee, M. M. C., Chang, K. S. F., and Chan, M. M. C. (1963). Sexual maturation of Chinese girls in Hong Kong. Pediatrics, 32, 389.

Marshall, W. A. (1966). Basic anthropometric measurements. In The Somatic Growth of the Child, p. 1. Ed. by J. J. van der Werff ten Bosch and A. Haak. Stenfert Kroese, Leyden.

- , and Tanner, J. M. (1968). Growth and physiological development during adolescence. Ann. Rev. Med., 19, 283.

Nicholson, A. B., and Hanley, C. (1953). Indices of physiological maturity, derivation and interrelationships. Child Develop., $24,3$.

Reynolds, E. L., and Wines, J. V. (1948). Individual differences in physical changes associated with adolescence in girls. Amer. F. Dis. Child., 75, 329.

Scott, J. A. (1961). Report on the Heights and Weights (and Other Measurements) of School Pupils in the County of London in 1959. London County Council, London.

Shuttleworth, F. K. (1939). The physical and mental growth of girls and boys age six to nineteen in relation to age at maximum growth. Monogr. Soc. Res. Child Develop., No. 3, Vol. 4. National Research Council, Washington.

Swan, A. (1969). Computing maximum likelihood estimates for parameters of the normal distribution from grouped and censored data. F. R. Statist. Soc. C., 18, No. 1 . In the press.

Tanner, J. M. (1962). Growth at Adolescence, 2nd ed. Blackwell, Oxford.

- (1969). Growth and endocrinology of the adolescent. In Endocrine and Genetic Diseases of Childhood, p. 19. Ed. by L. Gardner. Saunders, Philadelphia and London.

-, Whitehouse, R. H., and Takaishi, M. (1966). Standards from birth to maturity for height, weight, height velocity, and weight velocity: British children, 1965. Part I. Arch. Dis. Childh., 41, 454.

Correspondence to Dr. W. A. Marshall, Institute of Child Health, 30 Guilford St., London W.C.1. 